cystine calculi could be dissolved in vitro by the thiol-disulphide interaction.-I am, etc., J. M. WALSHE.

Department of Experimental Medicine, University of Cambridge.

REFERENCES

1 Adams, D. A., Goldman, R., Maxwell, M. H., Eldjaran, L., and Hambraeus, L., Scand. F. clin Lab. Invest., 1964, 16, 153. Hartley, B. S., and Walshe, J. M., Lancet, 1963

\section{Paroxysmal Heart Block on Exertion}

SIR,-I read with interest Drs. J. Gough and O. P. Galpin's paper on paroxysmal heart block on exertion (23 May, p. 1359). Exercise tests and other methods of auricular acceleration will bring to light many cases of type 2 partial heart block. In these cases there is a critical auricular rate, varying from patient to patient, above which the heart block occurs. In their patient it was concluded that only exercise induced heart block, but this may be because the drugs used to induce a block did not speed up the auricular rate sufficiently. The authors state that glyceryl trinitrate increased the heart rate to 100 beats per minute.

In four patients with type 2 heart block anginal pain and other symptoms were directly related to the onset of the heart block. $^{1}$ R. Froment and his colleagues report three cases of anginal pain associated with heart block that had no evidence of coronary-artery disease at post-mortem K. S. Smith and $M$. Zoob have shown that many cases of heart block in elderly patients are not due to ischaemia, the cause being unknown.

In type 1 partial heart block of the Wenckebach variety, with progressive lengthening of the PR interval and elimination of the block by exercise, the prognosis is good. In type 2 partial heart block with the fixed PR interval, brought on or aggravated by exercise, the prognosis is guarded. However, some of these patients have no ischaemic heart disease even when pain, dyspnoea, and faintness occur with the heart block. A profound haemodynamic disturbance must result from abrupt ventricular slowing at a time when there is a stimulus to accelerate which can only be accepted by the auricles. In some of these patients, as the one described by Drs. Gough and Galpin, with probably no coronary-artery disease, the condition may well be benign. Pronethalol may be successful in preventing these cardiac arrhythmias. - I am, etc.,

Charing Cross Hospital, P. B. S. Fow LER. London W.C.2.

\section{REFERENCES}

1 Fowler, P. B. S., Brit. med. f., 1962, 2, 1638. Froment, R., de Gevigney, D., Perrin, A., and Normand, J., Arch. Mal. Coeur, 1959, 52, 481 23, 458 .

\section{Anticoagulants in Rheumatic Heart Disease}

SIR,-Having read the paper by Dr. P. Szekely (9 May, p. 1209) on the use of anticoagulants for systemic embolism in rheumatic heart disease, I should like to pose the question, "At what stage after a cerebral embolus in the course of mitral stenosis should anticoagulation be initiated ?"

Cerebral infarcts are commonly haemorrhagic, ${ }^{1}$ and the present consensus of opinion is to avoid anticoagulation in cerebral thrombosis and infarction associated with atherosclerotic cerehrovascular disease. ${ }^{2}$ In the "insufficiency" syndromes hesitancy stems from the uncertainty of knowing whether significant infarction has occurred. A recent preliminary study indicated the possible value of the C.S.F. glutamic-oxaloacetic transaminase. ${ }^{3}$

In mitral stenosis $60 \%$ of emboli are cerebral, $20 \%$ are multiple, and $60 \%$ are recurrent. ${ }^{4}$ The majority occur within six months. In Dr. Szekely's series $40 \%$ of recurrences took place within one month. To practise medicine safely we must practise within the limits of our own experience. In the last six months I have seen only three cases of embolism associated with rheumatic heart disease and all were cerebral:

A man of 40 with mirral stenosis and incompetence and atrial fibrillation was admitted after sudden onset of a left hemiplegia. He was im mediately anticoagulated to safe levels with heparin, followed by phenindione, but became increasingly comatose and died with signs of brain-stem compression. Necropsy revealed massive haemorrhage in the right cerebral hemisphere, and blood had tracked down in the ventricles.

A woman of 55 with mitral stenosis, aortic incompetence, and atrial fibrillation was admitted with a right hemiplegia and was anticoagulated with heparin and phenindione to safe levels, and thereafter became increasingly comatose and died. Necropsy showed a massive haemorrhage in the left cerebral hemisphere, and blood had tracked down into the medulla.

A man of 37 with mitral stenosis and atria fibrillation was admitted with sudden onset of right hemiplegia to a hospital where there were no facilities for anticoagulation. Three weeks later, at a time when his hemiplegia was improving, he was anticoagulated and sent for valvotomy.

Such small experience is biased but sounds a note of extreme caution; no doubt others have experience to the contrary. How often is there recurrent cerebral infarction in the immediate post-embolus period? Is immediate anticoagulation safe or when does it become so? As an accessory to physical signs will enzyme studies enable us to determine whether a vessel occlusion has produced a large or small infarct?-I am, etc.,

Tamworth, Staffs. $\quad$ E. N. WARDLE.

\section{REPERENCES \\ Greenfield's Neuropathology, by W. Blackburn, W. H. McMenemey, A. Mayer, R. M. Norman,
and D. S. Russell, 1963, p. 83. Edward

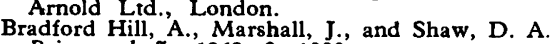 Brit. med. F., 1962, 2, 1003 \\ s Mellick, R. S., and Bassett, R. L., Lancet, 1964 1,904 . \\ Wood, $\mathrm{P}_{\text {. }}$, Diseases of the Heart and Circulation, London. \\ Neonatal Thrombocytopenia and Thiazide Drugs}

SIR,-Dr. L. F. Prescott commented (30 May, p. 1438) on the article "Controlled Trial of Chlorothiazide in the Treatment of Pre-eclampsia" by Mr. D. N. Menzies, in which he referred to a neonatal death due to thrombocytopenic purpura which could have been caused by chlorothiazide given to the mother. As stated in the original article, a subsequent sibling developed thrombocytopenia, although the mother had taken no chlorothiazide in this pregnancy. Antiglobulin consumption tests ${ }^{1}$ were carried out on the mother's blood after the birth of this second child, and showed an iso-platelet antibody capable of reacting with the father's platelets but not with her own. Owing to the large volume of blood required it was not possible to study the reaction of this second infant's platelets in the presence of the maternal antibody.

It seems likely that the thrombocytopenia was due to chlorothiazide in the first pregnancy, but was caused by iso-immunization in the second. These findings demonstrate the difficulty of assessing drug toxicity in the foetus.

A full account of these two cases with the haematological and pathological findings is to be published shortly.-I am, etc.,

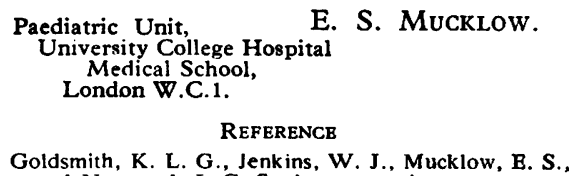
and Normand, I. C. S., in preparation.

\title{
Unmarried Mothers
}

SIR,-Dr. Freda M. L. Lucas's letter (30 May, p. 1442) touches on a long-standing controversy. She and her colleagues of the Metropolitan Counties Branch of the B.M.A. urge that unmarried pregnant women who propose to have their babies adopted should be told early in their antenatal care that they have the right to refuse to see or care for it from the moment of its birth. This summary pronouncement hardly does justice to the complexity of the emotional problem, or to the strength of the opposite view as to what is in the best interests of the mother and child.

Dr. Lucas refers to the psychiatric trauma which may be caused to the mother if she cares for the child. Those with much experience of the problem, on the whole, do not hold this view, but maintain that although the mother may have some suffering when she parts with the child this is less damaging and lasting when she knows that she has done her best for him during the early days of his life than if she has, as it were, disclaimed him utterly. ${ }^{2}$

Dr. Albertine Winner ${ }^{3}$ put the matter succinctly: "In the overwhelming majority of cases, she should have-in the interests of the child and herself - and in the long run of the adopters too-time to make up her mind in the full knowledge that she has done her best for her child. That of course is in conflict with the theory that if you take a child away immediately the mother does not mind; but .. that is not true: she does mind, and minds a great deal, and goes on minding, and very often has a sense of guilt that she has not done what she ought to have done." It is generally agreed that in the majority of cases the mother's decision to have the child 